Arq. Bras. Med. Vet. Zootec., v.68, n.4, p.913-918, 2016

\title{
Ciclooxygenase inhibitor and metronomic chemotherapy association for the treatment of metastatic anal sac carcinoma in dog: case report
}

\author{
[Inibidor de ciclo-oxigenase associado à quimioterapia metronômica no tratamento de carcinoma \\ de saco anal metastático canino: relato de caso] \\ N.C.T. Teixeira, A.P.C.V. Bicalho, A.V. Vasconcelos, R.S. Horta, \\ R.M.C. Cunha*, G.E. Lavalle \\ Escola de Veterinária - Universidade Federal de Minas Gerais - Belo Horizonte, MG
}

\begin{abstract}
Metronomic chemotherapy consists of an anticancer modality treatment. It is applicable in patients at an advanced stage, with the objective of increasing overall survival. The aim of this study was to report an anal sac apocrine carcinoma case in a dog with lymph node metastasis treated with metronomic chemotherapy sequential to surgery and conventional chemotherapy using gemcitabine and carboplatin. Metronomic chemotherapy was associated with cyclooxygenase-2 (COX-2) inhibitors, due to strong tumor COX-2 immunohistochemistry expression. Metronomic chemotherapy was initiated with cyclophosphamide, but it was replaced by lomustine, also in metronomic dosage, due to adverse effects. Treatment showed effectiveness, since the patient's overall survival exceeded 1095 days (36 months), considerably higher than the mean overall survival expected for this pathology.
\end{abstract}

Keywords: dog, oncology, angiogenesis inhibitor, cyclophosphamide, lomustine

\section{RESUMO}

Quimioterapia metronômica consiste em uma modalidade de tratamento anticancerígeno, aplicável a pacientes em estadiamento avançado, com o objetivo de aumentar a sobrevida global. O objetivo deste trabalho foi relatar um caso de carcinoma apócrino do saco anal, em uma cadela, com metástase em linfonodo tratado com quimioterapia metronômica sequencial à cirurgia e quimioterapia convencional utilizando-se gencitabina e carboplatina. O tratamento metronômico foi associado ao uso de inibidores de ciclo-oxigenase-2 (COX-2), baseando-se na constatação de sua expressão tumoral. A terapia metronômica iniciou-se com ciclofosfamida, mas houve necessidade de substituição pela lomustina, também em dose metronômica, devido à ocorrência de efeitos adversos. O tratamento mostrou ser eficaz, pois a sobrevida do paciente ultrapassa 1095 dias (36 meses) desde a cirurgia, sendo consideravelmente maior que a média relatada para essa patologia.

Palavras-chave: cão, oncologia, inibidor de angiogênese, ciclofosfamida, lomustina

\section{INTRODUCTION}

Canine anal sac apocrine carcinoma is a malignant tumor originated from apocrine glands on the anal sac walls. In dogs, it accounts for $17 \%$ of malignant perianal tumors (North and Banks, 2009). Metastases are frequent and occur in $50 \%$ to $80 \%$ of cases at the time of diagnosis

Recebido em 12 de maio de 2015

Aceito em 22 de dezembro de 2015

*Autor para correspondência (corresponding author)

E-mail: rubiamcc@gmail.com
(Bennett et al., 2002; Goldschmidt and Zoltowski, 1981).

Many treatment modalities have been described, although the best results are obtained through surgical excision of the primary tumor and affected lymph nodes, radiotherapy and chemotherapy with platinum derived cytotoxic agents. Outcome is extremely variable, probably due to the small number of reported cases and their heterogeneity (Poltons and Brearley, 2007). 
Veterinary Oncology has evolved in the past few years, and the number of patients treated with conventional chemotherapy using maximum tolerated doses (MTD) is increasing. Alternatively, there is a concurrent increase in metronomic chemotherapy interest. Metronomic chemotherapy is the continuous administration of chemotherapy drugs in significantly lower doses, without long breaks between sessions. It is applicable to patients in an advanced stage, with the goal of increasing overall survival (Kerbel and Kamen, 2004). This treatment modality may be synergistic with other antiangiogenic and targeted treatments, especially cyclooxygenase- 2 (COX-2) inhibitors (Horta et al., 2013).

The aim of this study was to report the association of metronomic chemotherapy and targeted therapy with COX-2 inhibitors to treat a dog with anal sac apocrine carcinoma with lymph node metastasis, after surgery and conventional chemotherapy.

\section{CASE REPORT}

A ten-year-old female Labrador retriever was first evaluated in October 2011 with a history of surgically treated mammary tumors, hypothyroidism treated with levothyroxine and a perianal nodule noticed by the owner 15 days earlier. The nodule was approximately $5 \mathrm{~cm}$ in diameter, fast growing, well delimitated, movable and firm.

Fine needle aspiration of the nodule was performed and subsequent cytology exam showed a malignant epithelial neoplasm. Preoperative laboratory exams were normal, except for abdominal ultrasound, which revealed an enlarged left medial iliac lymph node. Ultrasound images were suggestive of metastatic neoplasm process.

The patient was submitted to surgery to remove the perianal solid mass, which was adhered to the pelvic diaphragm, and the left medial iliac lymph node. The contralateral lymph node was not removed because it did not show size, shape or consistency changes.
Primary mass and lymph node were submitted to histopathological examination. Macroscopic exam of primary neoplasm revealed an eightcentimeter cystic mass, with petrous consistency, not ulcerated, but adhered to musculature. The left medial iliac lymph node was approximately $2.0 \mathrm{x} 3.0 \mathrm{~cm}$, cystic, with firm consistency, irregular surface and greyish color. Microscopic examination of the primary nodule revealed epithelial proliferation in tubular and solid disposition, with rosette formation and stromal invasion. Cells showed moderate anisocytosis and anisokaryosis with prominent nucleoli. Accentuated desmoplasia and intratubular necrosis were seen. Lymph node microscopic examination revealed epithelial proliferation with predominantly tubular and solid disposition. Accentuated intratumoral desmoplasia, peripheral lymphocytes and a thick connective tissue capsule were seen. Diagnosis was anal sac gland carcinoma with left medial iliac lymph node metastasis.

Immunohistochemistry expression of COX-2 and Ki-67 (proliferation index) were evaluated with rabbit anti-COX-2 human monoclonal antibody (clone SP21, dilution 1:10, Lab Vision, MI, USA) and mouse MIB-1 monoclonal antibody (Ki-67, dilution 1:25, Dako Cytomation, CA, USA), respectively. A strong and diffuse COX-2 immunoreactivity in $30 \%$ of neoplastic cells was seen. According to the classification proposed by Lavalle et al. (2009), neoplasm was classified with a score 6 for COX-2 (score ranging from zero to twelve). Proliferation index was $40 \%$ (Figure 1).

The patient was submitted to a second abdominal ultrasound 30 days after surgery and a $3.79 \mathrm{~cm}$, hypoechoic mass located on the aortic trifurcation was seen (Figure 1). The mass was compatible with an enlarged right medial iliac lymph node, suggestive of metastasis.

It was then decided to avoid a new surgical procedure. The patient was submitted to four cycles of chemotherapy with gemcitabine $\left(200 \mathrm{mg} / \mathrm{m}^{2}\right)$, intravenously, followed by carboplatin $\left(10 \mathrm{mg} \cdot \mathrm{kg}^{-1}\right)$, intravenously, four hours later. The interval between cycles was 21 days. 

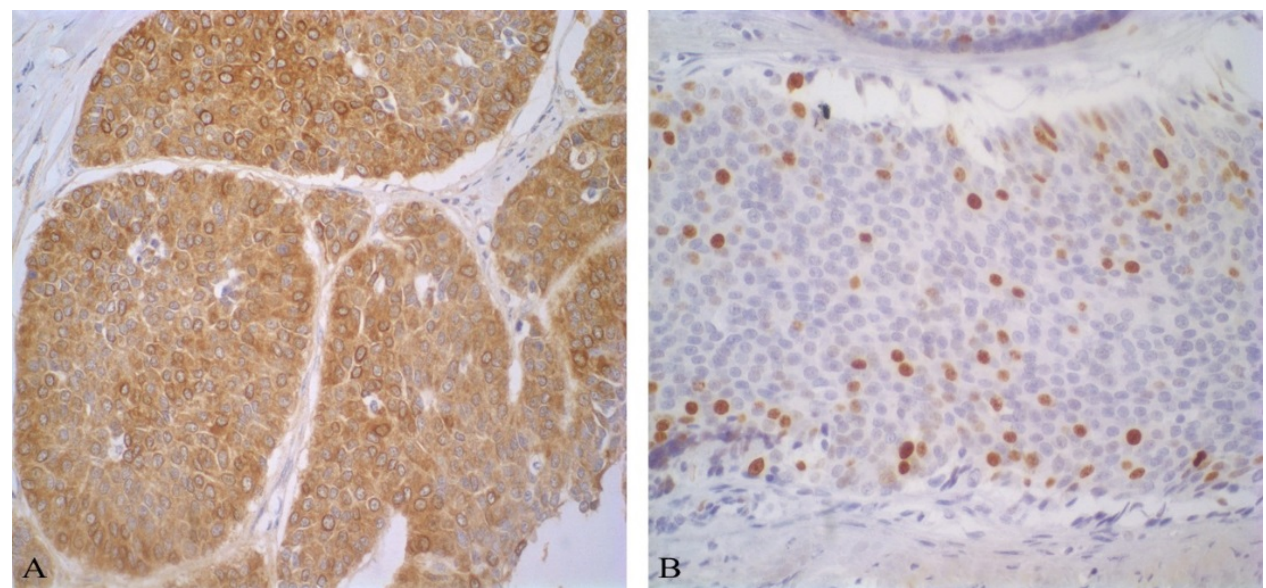

Figure 1. Anal sac gland carcinoma immunohistochemistry photomicrograph with anti-COX-2 (A) and MIB-1 (B). A strong and diffuse cytoplasmic immunoreactivity is seen in A (40x) and proliferation index was considered $40 \%$, with cytoplasmic immunoreactivity in B (40x).

After four cycles of MTD chemotherapy, metronomic chemotherapy was initiated with cyclophosphamide $\left(15 \mathrm{mg} / \mathrm{m}^{2}\right)$ associated with the cyclooxygenase- 2 inhibitor firocoxib $\left(5 \mathrm{mg} \cdot \mathrm{kg}^{-1}\right)$. High COX-2 immunohistochemistry score was also taken into account in the treatment decision. Both drugs were administered orally, every 24 hours.

Clinical follow-up was performed every 30 days for the first year, and then, every 60 days from the second year on. Follow-up consisted of complete physical examination, complete blood count, serum chemistry profile, thorax and lumbosacral radiographs and abdominal ultrasound. The patient was submitted to an abdominal ultrasound on September 2012, and right medial iliac lymph nodes measure was $4.13 \mathrm{~cm}$ (Fig. 2). Initial and final size variation is not significant, indicating a stable disease.
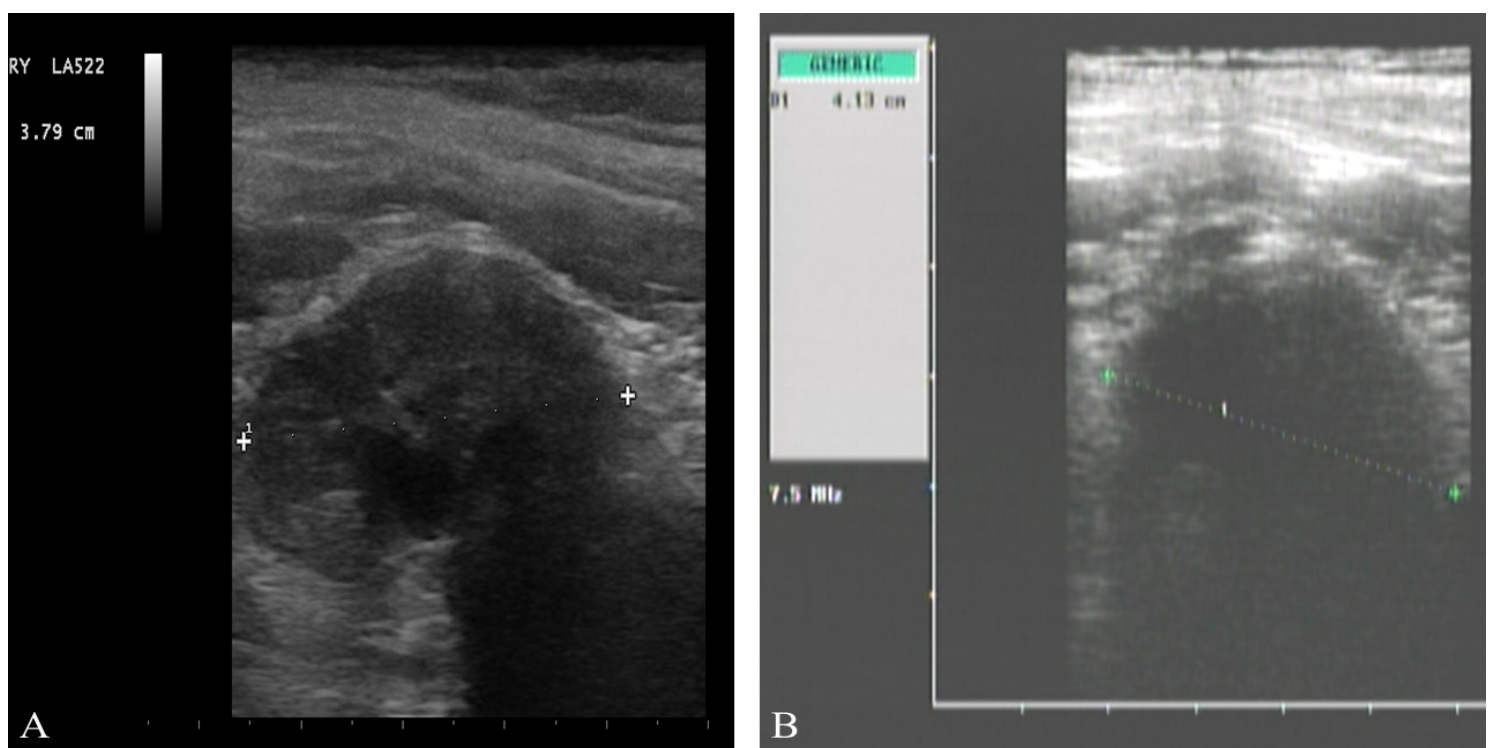

Figure 2. a) Ultrasound image of $3.79 \mathrm{~cm}$ right medial iliac lymph node suggestive of metastasis, on December $13^{\text {th }}, 2011$, previous to chemotherapy treatment; b) ultrasound image of $4.13 \mathrm{~cm}$ right medial iliac lymph node, on September $3^{\text {rd }}, 2012$, after chemotherapy treatment. Initial and final size variation is not significant, indicating a stable disease. 
Eleven months after the initiation of metronomic chemotherapy, the patient developed hemorrhagic cystitis, associated with continuous cyclophosphamide administration. At this moment, cyclophosphamide was replaced with lomustine $\left(3 \mathrm{mg} / \mathrm{m}^{2}\right)$, every 48 hours. Firocoxib administration was maintained. Clinical follow up was kept every 60 days.

Patient overall survival is over 1095 days (36 months), with a stable disease and without adverse effects due to treatment.

\section{DISCUSSION}

Perianal neoplasms are extremely common in dogs. Most of these neoplasms originate from sebaceous or apocrine circumanal glands (hepatoid glands) or from anal sac apocrine glands (Bennett et al., 2002). Hepatoid adenomas are responsible for $58 \%$ to $96 \%$ of perianal tumors. Male and female dogs have a similar risk for the development of anal sac apocrine carcinoma (Bennett et al., 2002; Poltons and Brearley, 2007).

Fine needle aspiration cytology was used as a diagnostic method, after the detection of a firm mass on the perianal region. Malignant epithelial neoplasm diagnosis is enough for surgical planning, however, definitive diagnosis and surgical margin evaluation can only be obtained with histopathology (North and Banks, 2009).

Anal sac carcinoma has an elevated metastatic potential, even for small tumors of up to $0.5 \mathrm{~cm}$. Regional lymph nodes are the most frequent site of metastasis (Goldschmidt and Zoltowski, 1981; Bennett et al., 2002). As such, medial iliac lymph nodes are the main lymph nodes with metastasis on anal sac carcinoma in dogs (Bennett et al., 2002). Distant metastasis may occur, late on the disease process, to liver, spleen, bones, heart, adrenal glands, pancreas, kidneys and mediastinum, so image exams are of utmost importance for disease staging (Goldschmidt and Zoltowski, 1981; Bennett et al., 2002). Thoracic radiographs are indicated to discard the possibility of pulmonary metastasis, while abdominal radiographs may indicate metastasis to vertebrae, evidenced by osseous lysis (North and Banks, 2009). Abdominal ultrasound is a sensitive and non-invasive method to detect shape and volume alterations in abdominal and pelvic lymph nodes, as well as for a detailed exam of abdominal organs (Bennett et al., 2002). According to Muramoto et al. (2011), the possibility of neoplastic involvement should be considered when there is ultrasonographic identification of lymph nodes with irregular and round shape, homogenous or heterogenous ecotexture, altered ecogenicity and elevated peripheral vascularization. High sensibility $(94.1 \%)$ and specificity $(92 \%)$ of ultrasound exam in differentiating metastatic from nonmetastatic lymph node in dogs with mammary neoplasms added to a high diagnostic agreement between ultrasonography and histopathology indicate that ultrasound is a reliable technique for lymph node evaluation.

Advanced image exams, such as computerized tomography (CT) and magnetic resonance (MR) may be very helpful to assess affected lymph node removal (Norht and Banks, 2009). However, due to the cost and availability limitations, these exams were not performed.

In the case reported here, the only clinical sign noted was a visible mass, adjacent to the anus. Common clinical signs attributed to perianal tumors include tenesmus and/or strain urination, thin shaped feces and constipation. Hypercalcemia is a paraneoplastic syndrome, with $25 \%$ to $50 \%$ incidence in patients with anal sac carcinoma. Hypercalcemia leads to polyuria and polydipsia, lethargy, anorexia and vomit (Bennett et al., 2002). Hypercalcemia was not noted in the patient in this case report, which had ionic calcium levels within normal range for the species.

Anal saculectomy is the indicated treatment for anal sac carcinoma removal. Regional lymph nodes with ultrasonographic alterations should be removed through exploratory laparotomy during the same surgical procedure, to stage the patient and prevent adherence formation and ulcerations (Bley et al., 2003).

Many agents such as carboplatin, cisplatin, melphalan and mitoxantrone have been used as adjuvant or palliative therapy, although their efficacy has not been well established (Bennet et al., 2002). Despite a reduced number of studies with radiotherapy, this seems to be the best treatment option for inoperable metastasis (North and Banks, 2009). Because the patient was 
considered in anadvanced stage, and radiotherapy was not available, carboplatin associated with gemcitabine was the treatment of choice, since single agent carboplatin is indicated for patients with residual disease (Bennet et al., 2002; North and Banks, 2009).

Conventional chemotherapy treatment in dogs and cats uses the same drugs used in Medicine protocols, including intervals and administration routes. However, Veterinarians and owners are not willing to submit veterinary patients to exacerbated side effects. As such, the aim is to administer tolerable doses, associated with minimum side effects. Therefore, Veterinary Medicine doses are smaller than doses used in Medicine, besides allometric extrapolation particularities between species (Mutsaers, 2009). The interval between chemotherapy sessions allows patients to recover, especially from bone marrow toxic effects. However, tumoral resistance to chemotherapy drugs may occur after initial treatment cycles (Rozados et al., 2004), which compromises treatment efficacy. This emphasizes the importance of different therapeutic approaches (Mutsaers, 2009).

Regarding disadvantages of high doses interspaced with long intervals, there has been a shift in chemotherapy treatment, with the possibility of administrating lower doses with shorter intervals. This therapy, defined as metronomic, results in a drastic reduction of toxic effects, and it may show great anti-tumor or anti-metastatic efficacy (Kerbel and Kamen, 2004; Rozados et al., 2004). While the objective of conventional chemotherapy is to stop tumoral cell proliferation, metronomic chemotherapy acts on growing endothelial cells, preventing tumoral angiogenesis. Besides this, metronomic chemotherapy allows association with other antiangiogenic drugs and even with targeted therapies (Kerbel and Kamen, 2004).

Amongst chemotherapy agents used in metronomic chemotherapy, the most frequently used is cyclophosphamide. Despite the low toxicity of this kind of protocol, it is known that some animals may develop non-infectious hemorrhagic cystitis, secondary to chronic cyclophosphamide administration (Kerbel and Kamen, 2004). This was observed in the case reported here, eleven months after the beginning of treatment. Clinical signs of remission were observed after treatment discontinuation. Lomustine also belongs to the alkylating agent class and it was an alternative drug in this case.

Cyclooxygenases are enzymes that catalyze prostaglandin synthesis from aracdonic acid, and two isoforms are identified: COX-1 and COX-2 (Knudsen et al., 2013). COX-1 is considered a constitutive enzyme, present in a variety of tissues. COX-2 is mainly expressed when it is induced by many stimuli, such as tumor promoters, oncogenes and carcinogens (Horta et al., 2013; Knudsen et al, 2013). High COX-2 levels in tumors may cause alterations in the cell cycle, through higher cell proliferation and development of new mutations (Knudsen et al., 2013). It may also promote angiogenesis in neoplastic processes through enhancement of prostaglandin production (Horta et al., 2013).

Knudsen et al. (2013) compared the expression of COX-2 in 25 samples of canine anal sac carcinomas and in 22 samples of healthy canine anal sacs. It was concluded that COX-2 is expressed in glandular epithelial cells of canine anal sac carcinoma and in non-neoplastic anal sac cells, which indicates that this enzyme may have a physiological role in this tissue. The result of this study and the elevated expression scores of COX-2 in the case reported here suggest future studies are necessary to evaluate usage of COX-2 inhibitors for the treatment of anal sac carcinoma as a single drug, combined with other drugs or after surgery.

Considering these results and the objectives of the target-therapy, COX-2 inhibitors are used to decrease prostaglandin levels, with a consequent reduction of angiogenesis and cell division. However, they should be used only after COX-2 expression is confirmed, so as not to add unnecessary morbidity due to COX-2 inhibitors side effects (Horta et al., 2013).

In the case reported here, high COX-2 score allowed the prediction of a favorable response to COX-2 selective inhibitors, such as firocoxib. Besides, there is synergy between this drug and metronomic chemotherapy, due to prostaglandin inhibition and a consequent reduction of proangiogenic factors (Horta et al., 2013; Knudsen et al, 2013). 
Anal sac carcinoma prognosis is related to patient staging and tumor size. Distant metastasis represents a poor prognosis (Poltons and Brearley, 2007). It is important to emphasize that the high number of proliferating cells $(40 \%)$ found in this case is also related to poor prognosis.

Bennet et al. (2002) reported overall survival of dogs with metastasis to be of six months, while dogs with initial staging had an overall survival of 11.5 months. In the case reported here, overall survival of 1095 days (36 months) is superior to mean overall survival found in literature. Although there are no studies of metronomic chemotherapy for the treatment of anal sac carcinoma, this seems to be a viable and efficient option for patients with inoperable metastasis.

\section{CONCLUSION}

The association of surgery, MTD chemotherapy and metronomic chemotherapy provided a longer overall survival to this one patient, with stable disease, no clinical signs and good life quality, which are the objectives of veterinary oncology. More studies are necessary to evaluate the effect of this treatment association in a larger population.

\section{REFERENCES}

BENNETT, P.F.; DENICOLA, D.B.; BONNEY, $\mathrm{P}$. et al. Canine anal sac adenocarcinomas: clinical presentation and response to therapy. $J$. Vet. Int. Med., v.16, p.100-104, 2002.

BLEY, C.R.; STANKEOVA, S.; SUMOVA, A. et al. Metastases of perianal gland carcinoma in a dog: palliative tumour therapy. Schweiz. Arch Tierheilkd., v.145, p.89-94, 2003.
GOLDSCHMIDT, M.H.; ZOLTOWSKI, C. Anal sac gland adenocarcinoma in the dog: 14 cases. J. Small Anim.Pract., v.22, p.119-128, 1981.

HORTA, R.S.; LAVALLE, G.E.; CAMPOS, C.B. Terapias de alvo-molecular. Cad. Téc. Med. Vet. Zootec., n.70, p.75-86, 2013.

KERBEL, R.S.; KAMEN, B.A. The antiangiogenic basis of metronomic chemotherapy. Nat. Rev., v.4, p.423-436, 2004.

KNUDSEN, C.S.; WILLIAMS, A.; BREARLEY, M.J.; DEMETRIOU, J.L. COX-2 expression in canine anal sac adenocarcinomas and in non-neoplastic canine anal sacs. Vet. J., v.197, p.782-787, 2013.

LAVALLE, G.E.; BERTAGNOLLI, A.C.; TAVARES, W.L.F.; CASSALI, G.D. Cox-2 expression in canine mammary carcinomas: correlation with angiogenesis and overall survival. Vet. Pathol., v.6, p.1275-1280, 2009.

MURAMOTO, C.; STERMAN, F.A.; HAGEN, S.C.F. et al. Avaliação ultrassonográfica de linfonodos na pesquisa de metástases de neoplasia mamária em cadelas. Pesqui. Vet. Bras., v.31, p.1006-1013, 2011.

MUTSAERS, A.J. Metronomic chemotherapy. Top. Companion Anim. Med., v.24, p.137-143, 2009.

NORTH, S.; BANKS, T. (Eds.). Introduction to small animal oncology. [s.1.]: Elsevier, 2009.

POLTONS, G. A.; BREARLEY, M. J. Clinical stage, therapy, and prognosis in canine anal sac gland carcinoma. J. Vet. Int. Med., v.21, p.274$280,2007$.

ROZADOS, V.R.; SANCHEZ, A.M.; GERVASONI, S.I. et al. Metronomic therapy with cyclophosphamide induces rat lymphoma and sarcoma regression, and is devoid of toxicity. Ann. Oncol., v.15, p.1543-1550, 2004. 